\title{
MUSCLE CLAMP FOR USE IN RECESSION OF THE INFERIOR OBLIQUE*
}

BY

\author{
A. B. NUTT AND O. O. FFOOKS \\ From the Royal Infirmary, Sheffield, and St. James's Hospital, Leeds
}

RFCFSSION of the inferior oblique has become a standard procedure in the surgical treatment of over-action of the inferior oblique muscle. The operation is most easily performed by placing a clamp (Fig. 1) on the inferior oblique next to its insertion, before removing the muscle (Ffooks, 1962).

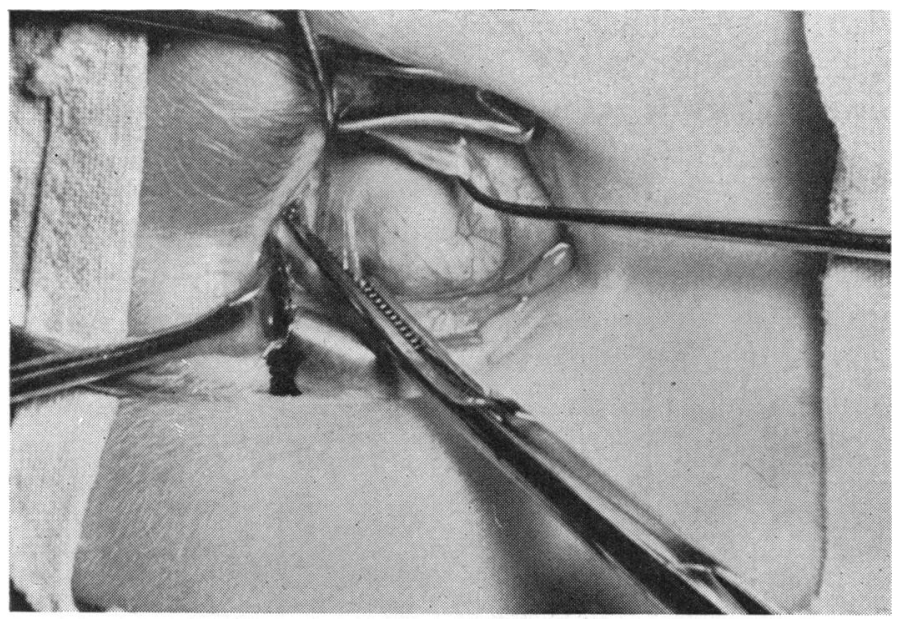

FIG. 1.-Clamp in position at insertion of the inferior oblique (From Ffooks, 1962, Fig. 4).

It is important to ensure a good fixation of the muscle without damaging the muscle fibres themselves. The fibres must be gripped, because the tendon of the muscle at its insertion is very short, and in order not to damage the muscle, one of us (A.B.N.) has devised a clamp for use in operations on the inferior oblique (Fig. 2).

FIG. 2.--Inferior oblique clamp. Jaws $\frac{1}{2}$ in length.

The clamp is obtainable from Messrs. Chas. Thackray Ltd.

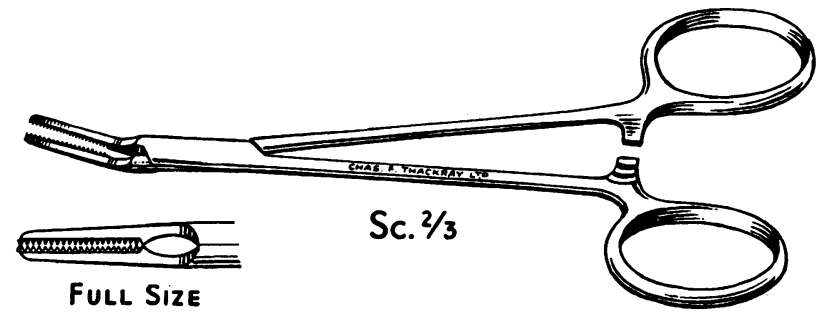

The instrument is a modification of a Potts aorta clamp. The very fine teeth do not meet at any point, but if they did, they would interdigitate. These teeth are sufficient to hold the muscle so that trauma to the fibres is reduced to an absolute minimum.

FFooKs, O. O. (1962). Brit. orthopt. J., 19, 90.

\section{REFERENCE}

* Received for publication April 3, 1963. 